\title{
Editorial
}

\section{New Challenges for International Archives of Otorhinolaryngology}

\author{
Geraldo Pereira Jotz ${ }^{1}$ \\ ${ }^{1}$ Editor-in-Chief, International Archives of Otorhinolaryngology \\ Int Arch Otorhinolaryngol 2013;17:357.
}

The International Archives of Otorhinolaryngology is beginning a new chapter in its history; starting with this issue, the journal will be published by Thieme Medical Publishers.

Much as impressionism, which emerged in the late 19th century in France, became the starting point for the development of modern art that conveyed the artists' desire to portray the moment in which a scene took place, the International Archives of Otorhinolaryngology has collaborated with Thieme to better disseminate its content, thereby providing more visibility for its authors. This is an important step in the growth of the journal.

The journal will maintain its subsections and will publish supplementary special issues that will accompany the main journal, the first of which will appear in July 2014. For future issues, we will be changing the system of online submission and review of the papers, which will be managed by ScholarOne (http://mc.manuscriptcentral.com/iaorl).

In 2014, we will continue our policy of rewarding articles in the area of meta-analysis that are published in our journal, because these studies form the basis for opinion-making regarding the most varied subjects.

In this issue, among the published studies, we highlight the studies related to adenotonsillectomy, rhinoplasty, sensorineural hearing loss, neurotology, allergy, and orofacial issues, seeking challenges, responses, and therapeutic suggestions for several disorders.
DOI http://dx.doi.org/ $10.1055 / \mathrm{s}-0033-1354576$. ISSN 1809-9777. 